\title{
Difficulties and Characteristics of Students from Developing Countries in Using American Libraries Ziming Liu
}

This study was designed to examine the difficulties of students from developing countries in using American libraries. Fifty-four, mostly Asian, students studying at the University of California, Berkeley, were interviewed. The results reveal that these students encountered numerous problems in using their school's libraries. The problems included insufficient English proficiency, making it difficult to understand library terminology and policy; unfamiliarity with American libraries' classification system, subject headings, reference works, and open stacks; and confusion when online catalogs and databases retrieve too many results. Students in natural sciences usually had fewer difficulties than those in humanities and social sciences. Others who encountered fewer difficulties were those who were more proficient in English and whose home countries were more strongly influenced by American culture. This paper also discusses the possible causes of plagiarism. Recommendations are offered for improving library services for foreign students.

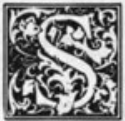

ince World War II, and especially since the 1970 s, the number of foreign students in American institutions of higher education has consistently increased. It has approximately doubled each decade. The number of foreign students rose from 100,000 in 1966 , to 203,000 in 1976 , to 356,187 in the $1987-88$ academic year. ${ }^{1}$ In 1984 , the United States ranked first worldwide in the number of foreign students enrolled at its universities. Thirty-two percent of the world's foreign students, or 342,110 students, were attending school in the United States. France followed with the next largest group of foreign students$133,848 .^{2}$ By the end of this century, the number of foreign students in the United
States could approach one million, and "the presence of foreign students could be one of the most powerful themes in American higher education," according to Malcolm G. Scully. ${ }^{3}$ Their presence is viewed by many American educators as a positive development because it could lead to a broader and deeper understanding among the nations and people of the world.

Foreign students in the United States come from approximately 180 countries. At one time, foreign students studying in the United States were predominantly from European countries, where the economy, language, and culture are similar to the United States' economy, language, and culture. Today, more students

Ziming Liu is a doctoral student at the School of Library and Information Studies, University of California, Berkeley, California 94720. The author acknowledges the help of many people, especially Professor Michael Buckland, Professor Yale Braunstein, and anonymous referees. This paper was supported in part by the Educational Improvement Grant Program, University of California, Berkeley. 
come from Asia, especially from China, India, Japan, and Korea. A 1989 report shows that, for the first time, Asian students constituted more than 50 percent of the total foreign students enrolled in the United States. The number of Asian students had increased from 143,680 to 180,500 between the $1984-85$ academic year and the 1987-88 academic year. Most of those students were from China $(51,830){ }^{4}$ Another study shows that, during the 1983-84 academic year, more than 60 percent of foreign students were from countries where English is neither an official language nor a medium of instruction. $^{5}$

Western Europeans tend to adjust most easily to the American academic environment because their social, educational, and library backgrounds are somewhat similar to those of American students. Students from other countries, particularly Asia, encounter more problems adjusting to the new environment because their backgrounds are different. They are not, for instance, familiar with the system used in libraries in the United States. This difference influences their expectation of library services and their adjustment to the new academic and cultural environment. ${ }^{6}$ Obviously, these students will encounter many problems, of which using the library is one. Undoubtedly, library skills are fundamental to their success in the new educational system.

Despite the growing number of foreign students in the United States, few librarians seem interested in discovering how to serve these students better. Much has been written about foreign students' library skills, but most of the literature has focused on library orientation and bibliographic instruction. The literature has given little attention to the problems of international students, particularly those from developing countries. Systematic analyses of difficulties and characteristics of foreign students are lacking. Two of the studies that address the problems are those done by Mary G. Lewis and Dania M. Bilal. In 1969, Lewis interviewed sixty Asian students from twenty different countries at the Univer- sity of Hawaii. She found that those students had fifteen types of difficulties in using the library. ${ }^{7}$ She also made suggestions for improving library services. In 1987, Bilal interviewed students at the Florida State University Center for Intensive English Studies who were studying English as a second language. Bilal examined the students' acquisition of library research skills in relation to their proficiency in English. ${ }^{8}$

\section{Despite the growing number of foreign students in the United States, few librarians seem interested in pursuing how to serve these students better.}

This article attempts to identify and analyze the problems and characteristics of students from developing countries in using American libraries. Suggestions are made on how to improve library services for this special segment in the academic community. The article addresses the following questions:

- What are the problems that foreign students face in using American libraries, and what are the cultural, educational, and psychological causes of these problems?

- How do the foreign students' previous environments affect their library use in America?

- How do foreign students cope with their difficulties in using the library?

- How can librarians improve library services for foreign students?

\section{METHODOLOGY}

Previous related studies relied upon mail questionnaires as the primary means to discover what had been done to orient new foreign students to libraries. ${ }^{9}$ For this study, in-person interviewing was employed because in-person interviews result in more answers and fewer misunderstood questions than self-administered questionnaires. Interviews are particularly appropriate for investigating foreign students with insufficient English proficiency because 
they allow for question clarification. ${ }^{10}$ Frank W. Goudy and Eugene Moushey stated that a "questionnaire often has severe limitations as a method for obtaining information necessary to present a full view of the issue at hand. Checking answers that provide a brief and predefined statement often limits respondents in communicating any unique situations that are relevant to their situation."11 Interview surveys can achieve a higher response rate than mail surveys and can be more effective in dealing with complicated issues, such as the characteristic style of library use of foreign students in using American libraries, the students' ability to speak English, and their reactions to the survey.

According to the research design, interview questions for the foreign students focused on their previous library experience and academic environments, their problems in using American libraries, their strategies in solving the problems, and their suggestions for improving library services.

Fifty-four foreign students studying at the University of California, Berkeley were interviewed. Included were fifteen doctoral students, twenty-three other graduate students, and sixteen undergraduate students. Thirty-three of the interviewees were majoring in natural sciences, and twenty-one were majoring in humanities and social sciences. They came from the following developing countries: Brazil, China, Egypt, India, Indonesia, Iran, Iraq, Korea, Malaysia, Mexico, Thailand, the Philippines, and the former Soviet Union. Thirty-two of them were selected from Asian students in order to match the characteristics of the international student population at the University of California, Berkeley, and at other academic institutions in the United States.

Four interviewees failed to answer the questions completely, because of their limited English and limited experience using the libraries. Interviews lasted between eighteen and seventy-five minutes, with the average interview being thirtyfive minutes.

A variety of problems arose in surveying students from different social and cultural contexts. These problems were avoided, in part, by speaking slowly and clearly, and avoiding idioms. Also, foreign students were interviewed in small groups so that students with good English proficiency could help to explain unclear responses from poor English speakers. In addition, talking with them in their native languages was helpful.

\section{FINDINGS AND DISCUSSION}

Depending on what part of the world they come from, foreign students face a variety of difficulties. The problems are described below.

\section{Language Barriers}

Although foreign students are usually required to pass a Test of English as a Foreign Language (TOEFL) before being enrolled in American colleges and universities, they still lack adequate English vocabulary, including library terminology. This hinders them from clearly and fully understanding a library's policies and practices. A common complaint from interviewees is that they could not fully understand what the librarian said during orientation tours. Limited communication skills and lack of confidence also makes them hesitate to ask for help in libraries. The survey showed that more than 50 percent of the interviewees often turned for help to their compatriots, instead of a librarian, for help when they faced problems.

\section{Not Accustomed to Open Stacks}

Using American libraries is a bewildering experience for many foreign students. Many libraries in developing countries have closed stacks, making the libraries more like study halls than places for research. For example, approximately 90 percent of the libraries in China have closed stacks, and only 20 to 40 percent of these libraries' collections are in open stacks. ${ }^{12}$ When students want to borrow a book, they have to submit a slip to the clerk and wait for the book to be given to them. This survey indicates that, during their first year in the United States, nearly 40 percent of the interviewees were unfamiliar with open 
stacks. Twenty-six percent of them did not know they may recall a book when it had been checked out. Book return procedures in some developing countries include a procedure for canceling the loan. Some foreign students said that they hesitated to place books in the return boxes for fear of being accused of not having returned the books.

\section{Many of them rarely ask reference questions because of their poor communication skills in English and the lack of attention to reference services in their home countries.}

Self-service often does not exist in many developing countries. It is no small wonder, therefore, that students from an environment in which library personnel make photocopies for them do not know how to operate photocopying machines effectively when they arrive in the United States. It is interesting to note, too, that more than sixty percent of the respondents had left their photocopying cards in the machines the first or second time they used them. Sally G. Wayman's study reported, "An international student leader told me that if I took a survey of international students, I would discover that they like our Map Section the best of all library departments because the Map's staff retrieves the maps and hands them out. As the only nonselfservice section of our library system, Maps meets their expectations of what library service should be." ${ }^{13}$ Many of them rarely ask reference questions because of their poor communication skills in English and the lack of attention to reference services in their home countries.

\section{Unfamiliar Classification System}

Most foreign students are unfamiliar with American classification and subject headings. Classification systems vary in some countries. For example, books on librarianship are classified in G in the Chinese standard classification, while they are grouped in $\mathrm{Z}$ by the Library of Congress (LC) Classification. Books on law are in $\mathrm{Z}$ according to Colon Classification (India), while they are classified in $\mathrm{K}$ in the LC, in D in China, and in $\mathrm{X}$ in the Soviet classification. The survey shows that about 45 percent of the interviewees were not familiar with the LC classification, and some had to find books by unsystematic searching. This process would naturally lead them to miss some of the most suitable books. Over 85 percent of them did not know how to use LC Subject Headings. In such cases, they had a habit of searching for a book by title instead of subject. Some students found the University of California's MELVYL online catalog to be effective in dealing with this problem because it provides for title keyword searching. The survey also revealed that there is little difficulty caused by changing classification from Dewey to LC, which presents a striking contrast to Lewis' findings in $1969 .{ }^{14}$ Both classifications are new to many respondents.

\section{Card Catalogs: Easier or Harder to Use?}

Some studies have revealed that foreign students have difficulties in using card catalogs. ${ }^{15}$ However, in this survey, more than 70 percent of the respondents thought that using American card catalogs is easier than using card catalogs in their home countries because American catalogs are in alphabetical order. Nearly half of them found that using the online catalogs is not difficult for them because there is a guidebook beside each terminal. Several students complained that they were confused when the database retrieved too many results. For example, on April 15, 1991, MELVYL retrieved 10,346 results on the subject American history, 3,725 results on biochemistry, and 613 on coastal ecology. One freshman complained she did not know how to choose a suitable book, and she said that she likes to choose books in two languages-English and her native language. Too many search results may cause trouble for new undergraduate students, but several doctoral students suggested they prefer too many results to very few. One doctoral student in biochemistry said, "One main reason why ] 
could pass the qualifying exam successfully is because I retrieved a considerable number of documents from MEDLINE. It includes almost all important works in biochemistry."

\section{Baffled by Reference Material}

The survey showed that foreign students, especially those in social sciences, knew little about American reference works. Graduate students in natural sciences were the exception. They said they could use American reference works effectively because they had already used some reference books, such as Biology $A b$ stracts, Chemical Abstracts, and Engineering Index before coming to the United States. Fifteen percent of them, however, still did not know how to find a journal article. In order to cope with this problem, some have a tendency to look for relevant articles cited by the papers they read. Employing this method, though, means that they will probably overlook some important articles.

\section{Too many search results may cause trouble for new undergraduate students, but several doctoral students suggested they prefer too many results to very few.}

The general impression of the survey is that students in natural sciences have fewer difficulties than those in humanities and social sciences. The main explanation is that natural sciences differ less across national boundaries than do social sciences.

\section{Poor English Proficiency}

The study also shows that, although foreign students must demonstrate adequate English proficiency before enrolling in college, few of them can read or converse with the accuracy and speed necessary for communication. Therefore, it is not surprising that, for those interviewed for this study, the better their English proficiency, the fewer difficulties they encountered in using the libraries. This result also coincides with several previous studies. ${ }^{16}$ The stronger the American influence on libraries in students' home countries, the fewer difficulties they found using American libraries.

\section{Plagiarism}

Another common problem amongst foreign students is plagiarism. According to Sally G. Wayman, "Plagiarism is a concept of which many foreign students are unaware, and, oblivious of penalties, they may unintentionally violate all rules of scholarship on their initial papers." ${ }^{17}$ Dick Feldman further explains, "In many countries, it is considered sufficient for students to show that they understand what the experts in their fields have written. In their written papers, students show that they have mastered the experts' ideas, and they can restate or synthesize those ideas coherently. As you can imagine, students from this tradition often encounter serious conflicts with our ideas of plagiarism."18 The same held true for this study.

It is worth noting that many foreign students in social sciences have a tendency to write something about their home countries because of their former educational background and interest. Many interviewees in this survey believed projects about their home countries are easier to complete and may be graded higher because professors are often not very familiar with students' home countries. The fact that some professors lack sufficient knowledge of students' home countries creates an opportunity for plagiarism.

\section{RECOMMENDATIONS}

1. In light of the findings in this survey, foreign students should be informed, before they start their studies in the United States, about the problems they might encounter in using American libraries. They could then be mentally prepared and avoid some frustration.

2. Glossaries of library terminology and handouts on the library's basic rules and procedures should be written in the students' native languages, as well as in English. If this is so, students with some 
basic knowledge of American libraries may have more self-confidence and be more willing to ask questions. Some Chinese students identified a leaflet in Chinese, "Introducing U.C. Berkeley Libraries to Chinese Users," as having been helpful for acquainting them with the library systems.

3. Tours of the library should be offered to foreign students. The tours should be bilingual or in the student's native language if the student does not fully understand spoken English. Also, those conducting the tours should articulate clearly and avoid library jargon. Another recommendation is for the tours to be done shortly after the student arrives on campus. It has been commonily accepted that the earlier the orientation, the easier the adjustment to the American academic environment. In addition, the tours should be done in small groups.

To help bridge the communication and cultural gap between foreign and American students, tour guides should be assisted by foreign students who are familiar in using American libraries. Several studies recommend doing so. ${ }^{19}$ Also, American students majoring in foreign languages, such as Chinese, Japanese, or Spanish, should help lead the tours. It has been widely accepted that students' English-language ability and social interaction are always intertwined. ${ }^{20}$ Claire Selltiz and others observed that for "the students studying in a foreign country, a thorough acquaintance with that country's language can be a valuable asset. Not only should it ease his academic task but also it should allow him to take more part in social life and to deal more easily with the small transactions and conversations that are part of everyday living in any community." ${ }^{21}$ One Chinese student said, "I think in Chinese, I live and work with Chinese, I watch Chinese TV programs, and I go shopping at Chinatown, so my
English have [sic] little improve [sic] since I came here." Undoubtedly, the better the students' English, the more likely they are to get involved in American culture and to improve their English further. Both are essential for foreign students' academic success in American education, and for getting needed encouragement and attention from Americans. ${ }^{22}$

4. Special hands-on workshops should be held to teach foreign students about the LC classification and subject headings, online catalogs, and library facilities, such as photocopying machines. Hands-on experience is direct and effective in overcoming communication barriers.

5. Library workers should become more sensitive to foreign students' special needs. Library staff commonly blame foreign students for their lack of familiarity with American libraries and for their English deficiency, while foreign students complain that library staff are insensitive. These two factors can exacerbate each other, as in the following scenario described by Irene Hoffman and Opritsa Popa: "A foreign student approaches the reference desk. In a quiet and retiring manner, the student asks for assistance. The librarian on the other side of the desk tenses while straining to understand the question through the heavily accented, soft-spoken voice of the student. The librarian becomes agitated, thinking why doesn't this student speak up? Why can't he speak English? The foreign student senses the librarian's distress, apologizes, and leaves without getting the needed information." ${ }^{23}$ This study is a step toward increasing such sensitivity. Terry A. Mood advocated that librarians should cultivate knowledge of students' homeculture, appreciate their differences, and establish close relationships with them. ${ }^{24}$ It is also necessary that those institutions with a substantial number of foreign students have library staff with a special responsibility for foreign students.

\section{REFERENCES AND NOTES}

1. National Center for Education Statistics, Digest of Education Statistics (Washington, D.C.: National Center for Education Statistics, 1980), 213; Institute of International Education, Open Doors, 1987/88 (New York: Institute of International Education, 1989), 1. 
2. Institute of International Education, Open Doors, $1987 / 88$.

3. Malcolm G. Scully, "One Million Foreign Students at U.S. Colleges Seen Likely by 1990," Chronicle of Higher Education 21(Oct. 1981):1.

4. Institute of International Education, Open Doors, $1987 / 88,1$.

5. Gina MacDonald and Elizabeth Sarkodie-Mensah, "ELS Students and American Libraries," College \& Research Libraries 49(Sept. 1988):425-31.

6. Terry A. Mood, "Foreign Students and the Academic Library," RQ 22(Winter 1982):17580.

7. Mary G. Lewis, "Library Orientation for Asian College Students," College \& Research Libraries 30(May 1969):267-72.

8. Dania M. Bilal, "International Students' Acquisition of Library Research Skills: Relationship with Their English Language Proficiency," Reference Librarian, 24(1989):129-45.

9. Laura S. Kline and Catherine M. Rod, "Library Orientation Programs for Foreign Students: A Survey," RQ 24(Winter 1984):210-16; Frank W. Goudy and Eugene Moushey, "Library Instruction and Foreign Students: A Survey of Opinions and Practices among Selected Libraries," Reference Librarian 10(Spring/Summer 1984):215-16.

10. Earl Babbie, The Practice of Social Research, 5th ed. (Belmont, Calif.: Wadsworth, 1989), 236-59; Ching-Chih Chen and Peter Hernon, Information Seeking, 1st ed. (New York: Neal-Schuman, 1982), 23-25.

11. Goudy and Moushey, "Library Instruction and Foreign Students," 217.

12. Zongzhong Huang, Introduction to Library Science (Wuhan: Wuhan Univ. Pr., 1987), 412.

13. Sally G. Wayman, "The International Student in the Academic Library," Journal of Academic Librarianship 9(Jan. 1984):336-41.

14. Lewis, "Library Orientation," 270.

15. Joan Ormondroyd, "The International Student and Course-integrated Instruction: The Librarian's Perspective," Research Strategies 7(Fall 1989):148-58; Lewis, "Library Orientation," 270.

16. Bilal, "International Students'," 129-45; Wayman, "The International Student in the Academic Library," 337.

17. Wayman, "The International Student in the Academic Library," 338.

18. Dick Feldman, "The International Student and Course-integrated Instruction: The ESL Instructor's Perspective," Research Strategies 7(Fall 1989):159-66.

19. Manuel D. Lopez, "Chinese Spoken Here: Foreign Language Library Orientation Tours," College \& Research Libraries News 44(Sept. 1983):268-69; Wayman, "The International Student in the Academic Library," 340.

20. Steven E. Deutsch, International Education and Exchange (Cleveland, Ohio: Pr. of Case Western Univ., 1970), 72-73.

21. Claire Selltiz and others, Attitudes and Social Relations of Foreign Students in the United States (Minneapolis: Univ. of Minnesota Pr., 1963), 124.

22. William F. Hull, Foreign Students in the United States of America (New York: Praeger, 1978); Judith M. Parisi, "Foreign Students: Relationship between Academic Achievement and Involvement in American Culture," Seminar paper, University of California, Berkeley, 1980.

23. Irene Hoffman and Opritsa Popa, "Library Orientation and Instruction for International Students: The University of California-Davis Experience," RQ 25(Spring 1986):356-60.

24. Mood, "Foreign Students and the Academic Library," 175-80. 


\section{TECHNOLOGY FOR THE 90's AND FOR THE LIBRARIES OF TOMORROW}

\section{BLACKWELL'S PROUDLY INTRODUCES...}

\section{FOR COLLECTION DEVELOPMENT}

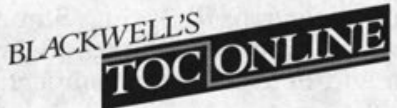

Blackwell's New Titles Online database now includes

Tables of Contents and Descriptive Summaries for new and forth-coming scholarly monographs.

- Browse the contents pages before placing the order

- View the publisher's title description

- Order the title electronically

- Insure a title is included on approval

- Access through the INTERNET

\section{FOR PUBLIC ACCESS CATALOGS BLACKWELL'S $\frac{505}{\mathrm{TOC} 505}$}

Blackwell's MARC With Books ${ }^{\circledast}$ service now offers LCMARC records enriched with Tables of Contents.

- Enhance subject access

- Improved chapter-level author access

- View contents \& summaries in your PAC before searching the shelves

- Increase interlibrary loan efficiency

FIND OUT HOW EASY AND COST EFFECTIVE IT CAN BE TO GET CONTENTS INFORMATION TO BOTH YOUR STAFF AND PATRONS TODAY!

\section{BLACKWELL \\ NORTH AMERICA, INC. \\ TECHNICAL SERVICES DIVISION}

